\title{
Effect of Aging on Endogenous Level of $5 \alpha$-Dihydrotestosterone, Testosterone, Estradiol, and Estrone in Epithelium and Stroma of Normal and Hyperplastic Human Prostate
}

\author{
MICHAEL KRIEG, RALF NASS, AND SABINE TUNN \\ Institute of Clinical Chemistry and Laboratory Medicine, University Clinic Bergmannsheil, Bochum; and \\ Medizinische Klinik (R.N.), Klinikum Innenstadt, Ludwig-Maximilians-Universität, München, Germany
}

\begin{abstract}
It is widely believed that benign prostatic hyperplasia (BPH) is associated with aging. Thus, the question arises whether or not a correlation exists between the well known prostatic androgen and estrogen accumulation and aging. To address this question, we measured $5 \alpha$-dihydrotestosterone (DHT), testosterone, estradiol, and estrone in epithelium and stroma of six normal (NPR) and $19 \mathrm{BPH}$ and correlated the values with the age of the donors (26-87 yr). The mean DHT level in NPR epithelium was significantly higher than in NPK stroma, and also significantly higher than in epithelium and stroma of BPH. The epithelial DHT level of NPR and BPH decreased with age, the correlation being statistically significant. The stromal DHT level
\end{abstract}

of NPR and BPH showed no correlation with age. Concerning testosterone, generally rather low values were found which showed no correlation with age. The mean levels of estradiol and estrone were significantly higher in BPH stroma as compared to BPH epithelium as well as to NPR epithelium and stroma. In NPR, the mean levels of estradiol and estrone were significantly higher in epithelium than stroma. In NPR and BPH, the stromal estradiol and estrone levels increased significantly with age. In epithelium such a correlation between the estrogen levels and age was not found. Our results indicate that the prostatic accumulation of DHT, estradiol, and estrone is in part intimately correlated with aging, leading with increasing age to a dramatic increase of the estrogen/androgen ratio particularly in stroma of BPH. (J Clin Endocrinol Metab 77: 375-381, 1993)
$\mathrm{C}$ linical trials are currently underway to lower the intracellular level of $5 \alpha$-dihydrotestosterone (DHT) and/or estrogens in benign prostatic hyperplasia (BPH) (1). The rational background for such clinical trials is the assumption that androgens are somehow involved in the development of BPH. In line herewith is the well documented finding that in BPH a manifold higher content of DHT as well as of estradiol and estrone is present than in the corresponding plasma and skeletal muscle $(2,3)$

However, the tremendous enrichment of DHT in whole tissue homogenate of $\mathrm{BPH}$ seems to be not a BPH specific phenomenon since nearly the same content has been found more recently in normal prostates (NPR) (4-7). But, lacking differences of DHT content in whole tissue homogenate from BPH and NPR do not exclude possible differences in DHT content between epithelium and stroma within the individual prostate as well as between NPR and BPH. Such differences could merit special interest because the embryonic stroma is essential for morphogenesis and growth of the rodent prostate. Furthermore, the mesenchyme rather than the epithelium is the major target for androgens $(8,9)$. Moreover, it has been postulated that in BPH an embryonic reawakening of the inductive potential of the prostatic stroma might occur (10).

Received August 11, 1992.

Address correspondence and requests for reprints to: Prof. Dr. M. Krieg, Institute of Clinical Chemistry and Laboratory Medicine, University Clinic Bergmannsheil, Gilsingstrasse, 14, D-4630 Bochum 1, Germany.
As yet, however, only a limited number of studies on DHT content in epithelium and stroma of NPR and BPH has been performed. The available data are rather inconsistent $(7,11$ 14). The same holds true for the estrogen content in $\mathrm{BPH}$ and NPR. As yet, it is unclear whether or not a BPH specific accumulation of estrogens occurs $(3,6)$. However, within the $\mathrm{BPH}$ it has been shown that the stroma contains about three times more estrone and estradiol than the epithelium (15). This is in keeping with the preferential detection of estrogen receptors in stroma of $\mathrm{BPH}(16,17)$. Therefore, it appears that the stromal compartment is the primary target for estrogenic action.

Although the development of BPH is associated with aging (18), as yet, it is only known that the DHT content measured in whole BPH tissue homogenates, does not correlate with age $(4,6)$. Corresponding age related studies on androgen and estrogen content in epithelium and stroma of NPR and $\mathrm{BPH}$ are still lacking.

\section{Materials and Methods}

\section{Chemicals}

$\left[{ }^{3} \mathrm{H}\right] \mathrm{DHT}$ (SA, 4.32 TBq/mmol), testosterone (SA, 6.66 TBq/mmol), estrone $(\mathrm{S} \Lambda, 3.14 \mathrm{TBq} / \mathrm{mmol})$, and estradiol $(\mathrm{S} \Lambda, 6.25 \mathrm{TBq} / \mathrm{mmol})$ were purchased from New England Nuclear (Boston, MA). Antisera to DHT testosterone, estradiol, and estrone were kindly provided by Schering AG (Berlin, Germany). Bond-elut columns (ODS, RP), eluent for high performance liquid chromatography (HPLC) and scintillation solution Ready-Solv HP were obtained from Inter Sciences (Frankfurt, Germany), Baker (Groß Gerau, Germany), and Beckman (Munich, Germany), re- 
spectively. All other chemicals were obtained from Merck AG (Darmstadt, Germany), Serva (Heidelberg, Germany), Ferak (Berlin, Germany), and Boehringer (Mannheim, Germany).

\section{Tissue preparation}

NPR tissue was obtained from 6 brain-dead kidney donors, aged 26$61 \mathrm{yr}$. Immediately after nephrectomy, the pelvis was chilled with ice and the prostate was removed within $30 \mathrm{~min}$. BPH tissue was obtained from 19 men, aged 64-87 yr, removed by suprapubic prostatectomy. For each donor a written consent for this study was given. The exstirpated tissue was immediately chilled in ice-cold $0.9 \% \mathrm{NaCl}$, cut into small pieces, and stored at $-196 \mathrm{C}$. Each tissue specimen was histologically proven.

Epithelium and stroma were separated mechanically from each other and homogenized as previously described (17). Acid phosphatase and hydroxyproline were measured as markers for epithelial and stromal elements, respectively. The data were nearly identical to those published earlier (19-21). In the present study the mean relative purity of epithelial and stromal fractions ranged from $81-94 \%$

\section{Steroid extraction and defatting}

Immediately before extraction of endogenous steroids, $2000 \mathrm{dpm}\left[{ }^{3} \mathrm{H}\right]$ DHT, testosterone, estradiol, and estrone, each, were added to the homogenates, derived from 2-4 g prostatic tissue, for the determination of steroid recovery. Steroids were extracted by ethyl ether, that has been added to the homogenates twice. The combined ether phases were dried under nitrogen and redissolved in $10 \mathrm{ml}$ methanol: $\mathrm{H}_{2} \mathrm{O}$ mixture (20:80; $\mathrm{vol} / \mathrm{vol}$ ). For defatting, the redissolved aliquots were passed through a Bond-elut column. The elution was performed with $3 \mathrm{ml}$ methanol. The eluates were dried under nitrogen and redissolved in $1 \mathrm{ml}$ acetonitrile: $\mathrm{H}_{2} \mathrm{O}$ mixture $(20: 80 ; \mathrm{vol} / \mathrm{vol})$.

\section{Separation of steroids by HPLC'}

The redissolved steroids were separated from each other by reversed phase HPLC (Pharmacia-LKB; column: Spherisorb, RP18, $3 \mu, 250 \mathrm{~mm}$. $4.6 \mathrm{~mm}$, ODS II, Melz, Berlin, Germany). The steroids were eluted with a mixture of acetonitrile:water (vol/vol) using a gradient (19 min: 40:60; $41 \mathrm{~min}$ : 50:50; $30 \mathrm{~min}: 40: 60$ ) at a flow rate of $1 \mathrm{ml} / \mathrm{min}$. Fractions of $0.5 \mathrm{ml}$ were collected. Under these conditions DHT (capacity factor, 6.2), testosterone (3.5), estradiol (3.1), and estrone (5.0) were clearly separated from each other.

Before routine assays were performed, several elution profiles of $\left[{ }^{3} \mathrm{H}\right] \mathrm{DHT}$, testosterone, estradiol, and estrone, respectively, have been documented by measuring the radioactivity in each eluted fraction. The reproducibility of the profiles was excellent. Moreover, after each set of routine assays again an elution profile with the aforementioned tritiated steroids were recorded in order to confirm indirectly the effectiveness of steroid separation of the preceded runs. The eluted steroids (DHT, testosterone, estradiol, estrone) were dried under nitrogen and redissolved in $600 \mu \mathrm{l}$ methanol:gelatine phosphate buffer $(10: 50 ; \mathrm{vol} / \mathrm{vol})$ and aliquoted for RIA. Up to this step, the mean recovery of [ ${ }^{3} \mathrm{HJDHT}$, testosterone, estradiol, and estrone, determined for each sample, was $66 \%, 78 \%, 64 \%$, and $81 \%$, respectively, with less than $\pm 10 \%$ deviation from run to run.

\section{RIA}

RIA was performed in duplicate. The redissolved aliquots were diluted with gelatine phosphate buffer 1:20, 1:4, 1:2, 1:2 (vol/vol) for the quantification of DHT, testosterone, estradiol, and estrone, respectively. Then, aliquots of $200 \mu \mathrm{l}$ were incubated with $100 \mu \mathrm{l}$ antisera plus a constant amount of the respective tritiated steroid (dissolved in $100 \mu \mathrm{l}$ ) for $12 \mathrm{~h}$. The following cross-reactivities were given: DHT antiserum with testosterone: $42 \%$; testosterone antiserum with DHT: $6.3 \%$; estradiol antiserum with estrone: $1.3 \%$; and estrone antiserum with estradiol: $3.2 \%$. Bound/free-separation was performed with dextran coated charcoal. The bound fraction was analyzed in a scintillation counter. The standard curves were obtained as outlined elsewhere (3). The recovery of DIIT, testosterone, estradiol, and estrone was $50 \%, 65 \%, 57 \%$, and $70 \%$, and the sensitivity of the standard curve (buffer blank $+2 \mathrm{so}$ ) was $8.0,7.0,2.6$, and $2.1 \mathrm{pg} /$ tube, respectively. Intraassay coefficient of variation ( $\% ; \mathrm{n}=5$ ) of DHT, testosterone, estradiol, and estrone was 14 , 7,7 , and 2 at mean concentrations (picogram per $g$ tissue) of 6600,159 , 41 , and 22 , respectively. Interassay coefficient of variation $(\% ; \mathrm{n}=5)$ of DHT, testosterone, estradiol, and estrone amounted to $17,7,7$, and 6 at mean concentrations (picogram per $g$ tissue) of $6060,191,52$, and 50 . respectively. In all byproducts of the mechanical separation of epithelium and stroma, steroid concentrations were in the range of buffer blanks.

\section{Other methods}

Protein was determined according to Lowry et al. (22) using BSA as standard. DNA was measured as described elsewhere (23). Acid phosphatase (EC 3.1.3.2) was measured according to Walter and Schütt (24) Hydroxyproline was measured as described previously (25). The results were analyzed by analysis of variance (ANOVA) with repeated measures. In case of significance, descriptive Student's $t$ test was used additionally. $P$ was considered significant at $P<0.05$. Regression lines were calculated by the method of least squares.

\section{Results}

$D H T$ and testosterone levels in epithelium and stroma of NPR and $B P H$

Based on significances by ANOVA $(P<0.001)$ and on Student's $t$ test, the mean DHT concentration (Table 1) was significantly higher $(P<0.001)$ in epithelium than in stroma of NPR. It was also significantly higher $(P$ at least $<0.05)$ than in epithelium and stroma of BPH. In BPH significant differences in the DHT content between epithelium and stroma were not found. Concerning testosterone (Table 1), no significant differences were found using ANOVA, although the mean testosterone concentration was higher in stroma than in epithelium of NPR. In BPH such difference between stroma and epithelium was only given when the values were based on DNA.

\section{Estradiol and estrone levels in epithelium and stroma of NPR and $B P H$}

Based on significances by ANOVA $(P<0.01)$ and on Student's $t$ test the mean estradiol concentration (Table 1) was significantly higher $(P$ at least $<0.05)$ in stroma than in epithelium of BPH. It was also significantly higher $(P$ at least $<0.05)$ than in epithelium and stroma of NPR. With regard to NPR, in epithelium higher estradiol levels were found, the difference being significantly $(P<0.01)$ when the values were based on protein. Concerning estrone (Table 1), generally the results were rather similar to those for estradiol.

\section{Correlation of I)HT and testosterone levels with age}

In Fig. 1 DHT (upper panel) and testosterone levels (lower panel) were plotted against the age of donors. A significantly negative correlation ( $P$ at least $<0.05$ ) was found for DHT in epithelium of both the NPR and $\mathrm{BPH}$. Moreover, a significantly negative correlation with age $(P<0.0001)$ was found when all DHT levels of the epithelium were taken together. In stroma, an age-dependent alteration of the DHT level was 
TABLE 1. Mean ( \pm SEM) endogenous concentration of DHT, testosterone, estradiol, and estrone in epithelium and stroma of NPR and BPH

\begin{tabular}{|c|c|c|c|c|c|c|c|c|c|c|}
\hline & & \multirow{2}{*}{$\mathrm{n}$} & \multicolumn{5}{|c|}{ (fmol/mg protein) } & \multicolumn{3}{|c|}{ (fmol/mg DNA) } \\
\hline & & & Epithelium & & Stroma & $\underset{S}{\text { SEM }}$ & Epithelium & & Stroma & $\underset{د}{\operatorname{SEM}}$ \\
\hline \multirow[t]{2}{*}{ DHT } & NPR & 6 & $1190 \pm 140$ & $\star$ & $404 \pm 78$ & 147 & $15900 \pm 1600$ & $\star$ & $8200 \pm 1400$ & 1410 \\
\hline & $\mathrm{BPH}$ & 19 & $610 \pm 80$ & & $433 \pm 48$ & 105 & $6900 \pm 110$ & & $8300 \pm 800$ & 1270 \\
\hline \multirow[t]{2}{*}{ Testosterone } & NPR & 5 & $19 \pm 2$ & & $37 \pm 6$ & 6 & $267 \pm 49$ & & $748 \pm 60$ & 78 \\
\hline & $\mathrm{BPH}$ & 15 & $24 \pm 2$ & & $29 \pm 4$ & 6 & $308 \pm 18$ & & $599 \pm 93$ & 104 \\
\hline \multirow[t]{2}{*}{ Estradiol } & NPR & 6 & $4.4 \pm 0.3$ & $\star$ & $\begin{array}{l}2.2 \pm 0.3 \\
\star\end{array}$ & 0.5 & $61 \pm 6$ & & $\begin{array}{l}49 \pm 14 \\
\star\end{array}$ & 11 \\
\hline & $\mathrm{BPH}$ & 19 & $3.5 \pm 0.4$ & $\star$ & $6.2 \pm 0.8$ & 1.0 & $44 \pm 6$ & $\star$ & $120 \pm 15$ & 14 \\
\hline \multirow[t]{2}{*}{ Estrone } & NPR & 5 & $4.1 \pm 0.4$ & $\star$ & $\begin{array}{l}0.9 \pm 0.2 \\
\star\end{array}$ & 0.6 & $58 \pm 12$ & $\star$ & $\begin{array}{l}19 \pm 5 \\
\star\end{array}$ & 14 \\
\hline & BPH & 15 & $4.9 \pm 0.4$ & $\star$ & $7.4 \pm 0.9$ & 0.8 & $60 \pm 6$ & $\star$ & $147 \pm 18$ & 17 \\
\hline
\end{tabular}

The star indicates a statistically (Student's $t$ test) significant difference. $P<0.05$ was considered as significant. SEM $\Delta$ is the difference of sEM between epithelium and stroma.

not found. Concerning the testosterone level, in no case an age-dependent alteration was found.

\section{Correlation of estradiol and estrone levels with age}

In Fig. 2 estradiol (upper panel) and estrone levels (lower panel) were plotted against the age of donors. A significantly positive correlation ( $P$ at least $<0.05$ ) was found for estradiol as well as estrone in stroma of both NPR and BPH. Moreover, a significantly positive correlation with age $(P<0.0001)$ was found when all estradiol or estrone levels of the stroma were taken together. In epithelium, no significant age-dependent alteration of estradiol and estrone levels was found.

\section{Discussion}

In a previous comparative study between epithelium and stroma of NPR and BPH (20), we have shown that the mean potential DHT-forming capacity of $5 \alpha$-reductase is highest in NPR epithelium. Furthermore, the epithelial DHT-forming capacity of $5 \alpha$-reductase decreases in a linear fashion with age, whereas in stroma the DHT-forming capacity of $5 \alpha$ reductase remains unaltered over the whole age range (15$86 \mathrm{yr}$ ). In excellent agreement with those study on $5 \alpha$ reductase is the present comparative study on androgen levels indicating that 1) the mean endogenous DHT content is highest in NPR epithelium, and 2) a linear decrease of the DHT content occurs in epithelium with age, whereas in stroma the DHT content remains rather constant over the whole age range $(26-87 \mathrm{yr})$. This agreement between $5 \alpha^{-}$ reductase activity and endogenous DHT levels supports our concept that the $5 \alpha$-reductase plays an overwhelming role regarding the DHT accumulation in $\operatorname{NPR}$ and $\operatorname{BPH}(20,21)$.

As yet, published data on DHT content in epithelium and stroma from NPR and BPH differ markedly from one report to another and even within the individual studies if the DHT content is based either on wet weight, soluble protein, or DNA (7, 11-14). Therefore, to date it is completely uncertain whether a higher, identical, or lower DHT content is present in stroma as compared to epithelium. Probably, besides nonstandardized methodological procedures with respect to harvesting of prostates and their separation in epithelium and stroma, a further reason for those inconsistent mean DHT levels in the literature might be the significant impact of aging on the DHT content in epithelium as shown in this study.

In regard to steroid levels and aging, as yet no systematic studies on epithelium and stroma of the human prostate were performed. It has only been reported that in unseparated whole $\mathrm{BPH}$ tissue the $\mathrm{DH}$ ' content does not correlate with age $(3,4,6)$. Taking into account that the BPH consists mainly of stroma (26), a lacking correlation between DHT content in whole BPH tissue and age is not contradictory to our study, because in stroma we also were unable to demonstrate an age-dependent correlation.

All in all, in stroma DH'T levels appear to be similar over the whole age range, whereas in epithelium the rather high DHT level in young specimens decreases linearily with age. That is, in epithelium of the human prostate a DHT deprivation with age occurs. Whether this age-dependent DHT deprivation in epithelium is causally linked to the fact that not the epithelium but the stroma becomes the major compartment in BPH remains to be determined. Furthermore, in view of tendenciously different slopes of the regression lines for NPR and BPH specimens, at present the question remains unanswered whether the age-dependent decrease of DHT content in epithelium is solely due to aging per se or at least in part also due to BPH specific processes. Finally, despite an age-dependent decrease of DHT content in epithelium, our data clearly indicate that up to about 70 yr the epithelial DHT level is as high as in stroma, or even higher.

Those high DHT levels are the target when treating BPH patients with $5 \alpha$-reductase inhibitor. In this respect, very recently it has been shown that such treatment of $\mathrm{BPH}$ patients causes a dramatic decrease of the intraprostatic DHT within a few days (27). This finding further supports our suggestion that the DHT accumulation in epithelium and stroma of the human prostate is mainly due to the intrapros- 
FIG. 1. Correlation between endogenous DHT (upper panel) and testosterone levels (lower panel) in epithelium and stroma of normal human prostate $(\square)$ and BPH ( $\square$ ) and the age of donors. The values are based either on protein (left) or on DNA (right). The significance of the age-related changes was determined by the coefficient of correlation $(r) . m$, slope of those regression lines which were statistically significant $(P$ at least $<0.05$ ).
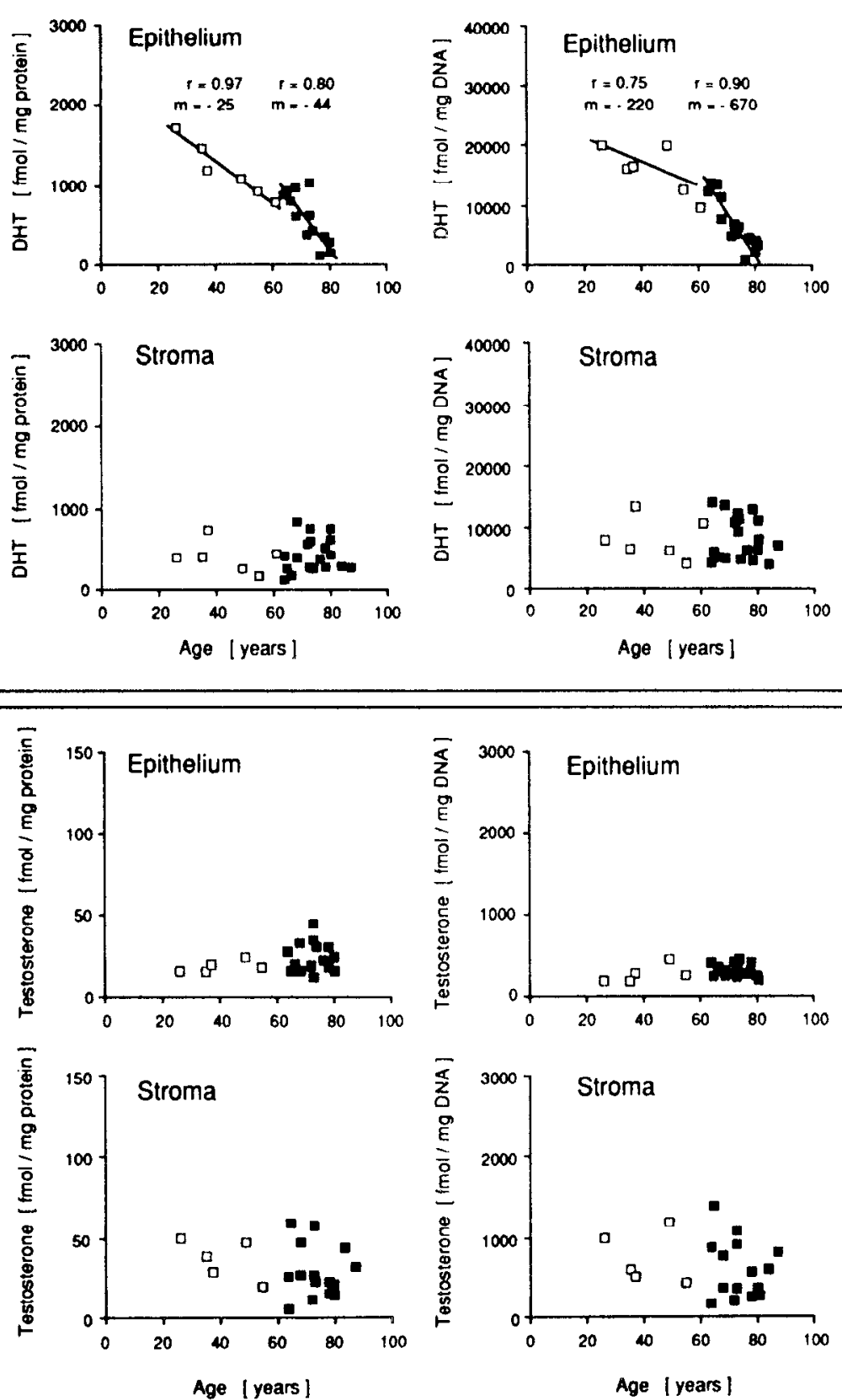

tatic $5 \alpha$-reductase activity. However, the possible pathobiological role of the tremendous DHT accumulation in the human prostate, that seems to be neither stroma nor $\mathrm{BPH}$ specific, remains unclear.

Besides the possible involvement of androgens in $\mathrm{BPH}$ development, numerous experiments indicate that estrogens might also be involved in the abnormal growth of the human prostate (1). In keeping with this assumption is the significant accumulation of estrone and estradiol in the human prostate when the levels are compared with those in plasma $(3,15$, 28) or in skeletal muscle (3). It is unclear, however, whether $\mathrm{BPH}$ tissue accumulates estrogens at a higher rate than NPR.
So far, either identical (6) or significantly higher levels (3) were found in BPH than in NPR. Interestingly, in the latter study it has been further reported that BPH samples that were predominantly stromal hyperplasia frequently showed the highest estrogen levels. This observation is in agreement with another study in which estrogens are predominantly enriched in BPH stroma (15). The present study, including for the first time the measurement of estrogens in epithelium and stroma of NPR, confirms the aforementioned significantly higher estrogen accumulation in BPH stroma as compared to epithelium. According to our study, such striking difference in the mean estrogen level between epithelium 
Fig. 2. Correlation between endogenous estradiol (upper panel) and estrone levels (lower panel) in epithelium and stroma of normal human prostate ( $\square$ ) and BPH ( $\square$ ) and the age of donors. The values are based either on protein (left) or on DNA (right). The significance of by the coefficient or correlation $(\mathrm{r}) \mathrm{m}$, slope of those regression lines which were statistically significant $(P$ at least $<0.05$ ). the age-related changes was determined
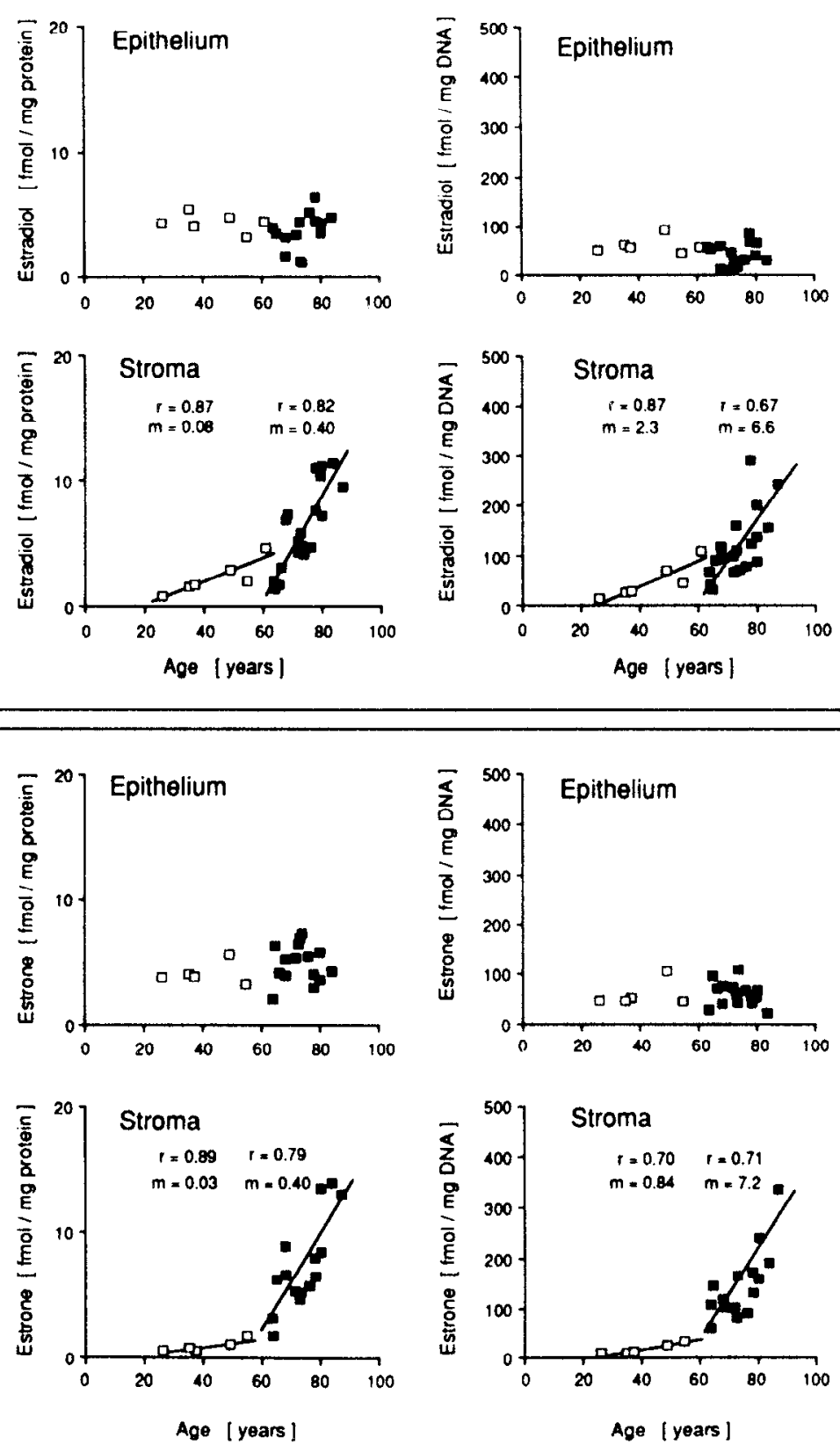

and stroma of BPH are due to the dramatic increase of the estradiol and estrone content with increasing age. In NPR stroma a similar age-dependent increase of the estrogen content occurs. However, despite this increase with age in NPR stroma the mean estradiol and estrone content remains significantly lower than in epithelium.

In stroma of normal as well as hyperplastic prostate an age-dependent increase of estrone and estradiol content occurs. Thus, aging per se might have a specific impact on the estrogen accumulation in human prostate. Moreover, since the regression lines are considerably steeper for $\mathrm{BPH}$ than NPR, BPH specific processes might additionally be involved.
In this respect, estrogen receptors have to be considered as one major candidate through which the estrogen accumulation is caused. Estrophilic proteins have been described in the human prostate (29). Furthermore, they seem to be preferentially located in BPH stroma $(16,17)$. Besides estrogen receptors it is also conceivable that enzymes like aromatase $(30,31)$, steroid sulfate sulfatase (32), and 17/-hydroxysteroid dehydrogenase (33) are causally linked to estrogen accumulation in human prostate. However, the actual cellular events leading to the asymmetric estrogen accumulation in epithelium and stroma of NRP and BPH are far from being understood. 
Finally, it is remarkable that the age-dependent decrease of DHT level in epithelium and the concomitant increase of estrone and estradiol level in stroma will lead to a tremendous increase with age of the estrogen/androgen ratio particularly in the stroma of human prostate. That is, the potential pathobiological role of estrogens for the human prostate could become stronger with age. This, in turn, could be of pathogenetic importance for BPH development if in fact a balanced estrogen/androgen synergism is necessary for integrity and normal growth of the prostate (1).

Regardless of whether androgens and estrogens act synergistically or independently from each other in $\mathrm{BPH}$, the high estrogen levels particularly in BPH stroma might justify the treatment of BPH patients with an aromatase inhibitor. Such trials, being currently underway, are promising due to animal experiments in which an aromatase inhibitor is in fact able to antagonize the estrogen related stimulation of fibromuscular stroma in prostates from intact beagle dogs (34). However, the final outcome of treating BPH patients with aromatase inhibitors are as yet unknown.

\section{Acknowledgments}

We wish to thank Dr. H. Schulze (Department of Urology, University Clinic Marienhospital, Herne, Germany) for supplying us with prostatic tissue. We are grateful to Dr. U. Habenicht (Schering $A G$, Berlin, Germany) and her technical staff for the generous gift of antisteroid antibodies for the RIA of DHT, testosterone, estradiol, and estrone Furthermore, we wish to thank Dr. J. Windeler (Department of Medical Statistics, University of Bochum, Germany) for his statistical advise.

\section{References}

1. Krieg M, Tunn S. 1990 Androgens and human benign prostatic hyperplasia (BPH). In: Nieschlag E, Behre HM, eds. Testosterone: action, deficiency, substitution, Berlin: Springer-Verlag; $219-244$.

2. Krieg M, Bartsch W, Herzer S, Becker H, Voigt KD. 1977 Quantification of androgen binding, androgen tissue levels, and sex hormone-binding globulin in prostate, muscle and plasma of patients with benign prostatic hypertrophy. Acta Endocrinol (Copenh). 86:200-215

3. Belis JA. 1980 Methodological basis for the radioimmunoassay of endogenous steroids in human prostatic tissue. Invest Urol. 17:332336.

4. Walsh PC, Hutchins GM, Ewing LL. 1983 Tissue content of dihydrotestosterone in human prostatic hyperplasia is not supranormal. I Clin Invest. 72:1772-1777.

5. Voigt KD, Bartsch W. 1986 Intratissular androgens in benign prostatic hyperplasia and prostatic cancer. J Steroid Biochem. 25:749757

6. Bartsch G, Keen F, Daxenbichler G, et al. 1987 Correlation of biochemical (receptors, endogenous tissue hormones) and quantitative morphologic (stereologic) findings in normal and hyperplastic human prostates. J Urol. 137:559-564.

7. Bruchovsky N, Rennie PS, Frederick HB, Goldenberg SL, Fletcher T, McLoughlin MG. 1988 Kinetic parameters of $5 \alpha$-reductase activity in stroma and epithelium of normal, hyperplastic, and carcinomatous human prostates. J Clin Endocrinol Metab. 67:806-816

8. Takeda H, Lasnitzki I, Mizuno T. 1986 Analysis of prostatic bud induction by brief androgen treatment in the fetal rat urogenital sinus. J Endocrinol. 110:467-470.

9. Cunha GR, Donjacour AA, Cooke PS, Bigsby RM, Sugimura Y. 1987 Stromal factors in the development and control of growth in the prostate. In: Rodgers CH, Coffey DS, Cunha G, Grayhack JT, Hinman $F$, Horton $R$, eds. Benign prostatic hyperplasia, vol II Bethesda: NIH publication no $87-2881 ; 15-25$
10. McNeal JE. 1978 Origin and evolution of benign prostatic enlargement. Invest Urol. 15:340-345

11. Sirett DAN, Cowan SK, Janecko AE, Grant JK, Glen ES. 1980 Prostatic tissue distribution of $17 \beta$-hydroxy-5 $\alpha$-androstan-3-one and of androgen receptors in benign hvperplasia. I Steroid Biochem. 13:723-728

12. Bolton NJ, Lahtonen R, Hammond GL, Vihko R. 1981 Distribution and concentrations of androgens in epithelial and stromal compartments of the human benign hypertrophic prostate. J Endocrinol 90:125-131

13. Bartsch W, Krieg M, Becker H, Mohrmann J, Voigt KD. 1982 Endogenous androgen levels in epithelium and stroma of human benign prostatic hyperplasia and normal prostate. Acta Endocrinol (Copenh). 100:634-640

14. Lahtonen R, Bolton NJ, Lukkarinen O, Vihko R. 1983 Androgen concentrations in epithelial and stromal cell nuclei of human benign prostatic hypertrophic tissues. J Endocrinol 99:409-414.

15. Kozak I, Bartsch W, Krieg M, Voigt KD. 1982 Nuclei of stroma. Site of highest estrogen concentration in human benign prostatic hyperplasia. Prostate. 3:433-438.

16. Bashirelahi N, Young JD, Sidh SM, Sanefuji H. 1980 Androgen, oestrogen and progestogen and their distribution in epithelial and stromal cells of human prostate. In: Schröder $\mathrm{FH}$, de Voogt HJ, eds. Steroid receptors, metabolism and prostatic cancer. Amsterdam: Excerpta Medica; 240:255.

17. Krieg M, Klötzl G, Kaufmann J, Voigt KD. 1981 Stroma of human benign prostatic hyperplasia: preferential tissue for androgen metabolism and oestrogen binding. Acta Endocrinol (Copenh). 96: 422-432.

18. Berry SJ, Coffey DS, Walsh PC, Ewing LL. 1984 Development of benign prostatic hyperplasia with age. J Urol. 132:474-479

19. Tunn S, Claus S, Schulze H, Braun BE, Krieg M. $19875 i x$ Androstane-3 $3,17 \beta$-diol hydroxylating enzymes in stroma and epithelium of human benign prostatic hyperplasia (BPH). I Steroid Biochem. 28:257-265

20. Tunn S, Hochstrate H, Grunwald I, Flüchter SH, Krieg M. 1988 Effect of aging on kinetic parameters of $5 \alpha$-reductase in epithelium and stroma of normal and hyperplastic human prostate. J Clin Endocrinol Metab. 67:979-985

21. Tunn S, Haumann R, Hey J, Flüchter SH, Krieg M. 1990 Effect of aging on kinetic parameters of $3 \alpha(\beta)$-hydroxysteroid oxidoreductases in epithelium and stroma of human normal and hyperplastic prostate. J Clin Endocrinol Metab. 71:732-739.

22. Lowry OH, Rosebrough NJ, Farr AL, Randall RJ. 1951 Protein measurement with the folin phenol reagent. J Biol Chem. 193: $265-275$.

23. Labarca C, Paigen K. 1980 A simple, rapid, and sensitive DNA assay procedure. Anal Biochem. 102:344-352.

24. Walter K, Schütt C. 1970 Saure and alkalische phosphatase in serum (Zwei-Punkt-Methode). In: Bergmeyer HU, ed. Methoden der enzymatischen analysen, vol 1. Weinheim: Verlag Chemie; $818-822$.

25. Stegemann H. 1958 Mikrobestimmung von hydroxyprolin mit chloramin $T$ und $p$-dimethylaminobenzaldehyd. Hoppe Seyler's $Z$ Physiol Chem. 311:41-45.

26. Bartsch G, Rohr HP. 1983 Androgen levels and binding in benign prostatic hyperplasia. In: Hinman $F$, ed. Benign prostatic hypertrophy. New York: Springer-Verlag; 235-247.

27. McConnell JD, Wilson JD, George FW, Geller J, Pappas F, Stoner E. 1992 Finasteride, an inhibitor of $5 \alpha$-reductase, suppresses prostatic dihydrotestosterone in men with benign prostatic hyperplasia. J Clin Endocrinol Metab. 74:505-508

28. Ghanadian R, Puah CM. 1981 Relationships between oestradiol$17 \beta$, testosterone, dihydrotestosterone and $5 \alpha$-androstane- $3 \alpha, 17 \beta$ diol in human benign hypertrophy and carcinoma of the prostate. $J$ Endocrinol. 88:255-262.

29. Ekman P, Barrack ER, Greene GL, Jensen EV, Walsh PC. 1983 Estrogen receptors in human prostate: Evidence for multiple binding sites. J Clin Endocrinol Metab. 57:166-176.

30. Kaburagi Y, Marino MB, Kirdani RY, Greco JP, Karr JP, Sandberg AA. The possibility of aromatization of androgen in human prostate. 1 Steroid Biochem. 26:739-742. 
31. Bartsch W, Klein H, Stürenburg HJ, Voigt KD. 1987 Metabolism of androgens in human benign prostatic hyperplasia: aromatase and its inhibition. I Steroid Biochem. 27:557-564.

32. Klein H, Molwitz T, Bartsch W. 1989 Steroid sulfate sulfatase in human benign prostatic hyperplasia: characterization and quantification of the enzyme in epithelium and stroma. J Steroid Biochem. 33:195-200.

33. Bartsch W, Greeve J, Voigt KD. 1987 17 3 -Hydroxysteroid dehy- drogenase in the human prostate: properties and distribution between epithelium and stroma in benign hyperplastic tissue. ] Steroid Biochem. 28:35-42.

34. Habenicht UF, E1 Etreby MF. 1989 Selective inhibition of androstenedione-induced prostate growth in intact beagle dogs by a combined treatment with the antiandrogen cyproterone acetate and the aromatase inhibitor 1-methyl-androsta-1,4-diene-3,17-dione (1methyl-ADD). Prostate. 14:309-322. 